\title{
Farmer First Research: A review of phase one results in relation to farmers' willingness and ability to change
}

J.I. REID, A.F. MCRAE and R. BRAZENDALE

Department of Agricultural and Horticultural Systems Management, Massey University, Palmerston North

\section{A bstract}

Formal knowledge of the goals, circumstances and constraints of a random sample of hill country sheep and beef farmers has been established. This knowledge was gathered, in collaboration with farmers from the Taihape/Hunterville and coastal Hawkes Bay regions, during phase one of the Farmer First Research programme based at Massey University. The data show that $75 \%$ of the farmers, in the study were willing to make changes to increase the profitability of their current farming system. However, although willing to change, 53\% were unable to do so because of constraints they faced. Two of these major constraints identified by farmers were high debt and a low incomegenerating under-developed farm. Both of these constraints contributed to an inadequacy of cash for the farmer. The other major constraints identified were labour, an ownership structure which limited the farmers' decision-making role in the property and the relatively low production potential of their farms. Phase one data indicate that farmers would be more likely to adopt new technologies and implement change if the changes addressed the farmers' constraints and were appropriate to the circumstances of the farmer.

K eywords: change constraints, Farmer First Research, farmer circumstances, goals

\section{Introduction}

The primary concern of farmers is to provide sufficient cash to ensure the wellbeing and security of their families (Fairweather et al. 1990). Since 1985 New Zealand hill country farmers have suffered lower terms of exchange (NZMWBES 1991a; Reynolds et al. 1990) and their ability to generate sufficient cash from their farm businesses has been put under pressure. In these circumstances it is expected that farmers will have taken advantage of any opportunity to increase productivity and profitability, including those opportunities offered by research.

The case for agricultural research is frequently argued in terms of the potential increases in productivity and profitability that will be afforded the user of the new research. Seventy percent of the scientists who presented papers at this conference last year justified their work on the basis that it would improve on-farm productivity. The validity of this argument has been questioned by a number of bodies responsible for the allocation of research funds.

The Science and Technology Expert Panel stated "the indications are that the uptake of technology is confined (in the area of sheep production) to a relatively small group of well-educated farmers" (The Science and Technology Expert Panel 1992). There is, however, very little formal information available about how farmers have responded to the economic pressures of the past 8 years. Further, the information that does exist takes little account of what farmers are trying to achieve, and the circumstances under which they operate.

The Farmer First Research (FFR) programme, based at Massey University, is attempting to complement the contribution research makes to the New Zealand agricultural industry (McRae et al. 1993). The FFR method being developed and tested in this programme has two phases. Phase one involves close collaboration with farmers to establish formally their goals and circumstances. Phase two is concerned with the design and evaluation of strategies that are appropriate to the goals and circumstances of farmers. This phase will be completed with the continued collaboration of farmers as well as scientists and others from the agricultural industry.

This paper reports on preliminary results from phase one of the FFR programme. The physical and financial circumstances of a random sample of sheep and beef farmers from Taihape/Hunterville and Hawkes Bay are described. The farmers' willingness and ability to change are discussed in relation to their circumstances. For those farmers willing but unable to change, the major constraints limiting change are identified. The ability of farm businesses to generate sufficient cash to meet the family's consumption needs are also outlined and discussed.

\section{$M$ ethod}

Two random groups of collaborating sheep and beef farmers were established in two climatically distinct regions of North Island hill country: summer moist 
Taihape/Hunterville and summer dry coastal Hawkes Bay. The unit of selection in each region was farms greater than 200 ha total farm size and corresponding to the characteristics of the NZ Meat and Wool Board Economic Service (NZMWBES) class 4 sheep and beef hill country farms.

The list of farms from which the selection was made were sourced from local authority records. Thirty properties, at least $10 \%$ of the population from each region, were selected at random from each of these lists. The current farmers of these farms (owner operators or managers) were identified with the assistance of local authority records and industry personnel from each region.

From the original 30 farms selected from each region 3 farmers from each region were not willing to participate in the research. The farmers of the three farms subsequently selected, from both regions, were willing to participate.

Two research officers, one working in each area, have completed phase one of the research programme. Three semi-structured interviews were carried out over 12 months, during which time the farmer established and confirmed with the research officer a full description of the physical, financial and personal circumstances of the farm and farm family since 1982 . The current goals of the farmer were also established.

To investigate the production-profitability relationship within the farming systems of the FFR sample, the combined sample was grouped into three subgroups, corresponding to high, medium and low profitability. Farm surplus per ha (farm income less farm expenses excluding interest and rent) was used as the measure of profitability. Total farm surplus is the balance of cash available to the farming family to service debt, pay tax and meet the family's consumption needs. The residual is then available for increased consumption or reinvestment. The Taihape/Hunterville and Hawkes Bay sample results were combined for the analysis, as wool production and wool income were the only indices to differ significantly $(\mathbf{P}<0.05)$.

Physical and financial data were analysed and compared using Duncan's multiple range test in SPSS/ PC (Norusis 1988).

\section{Results}

\section{NZMWBES sample - industry standard}

The NZMWBES carries out, and reports on, an annual survey of sheep and beef farmers. The class 4 North Island hill country category corresponds to the farms involved in the FFR programme and is presented as an industry standard comparison (NZMWBES 1992b).

A comparison of the physical and financial indices for the FFR and NZMWBES farms are provided in Tables 1 and 2. The NZMWBES sample mean differed from the FFR sample mean in two major indices, those of farm size and percentage of sheep stock units wintered. The FFR mean farm size (538 ha) was $44 \%$ larger than the NZMWBES mean farm size (374 ha). The FFR farms wintered $12 \%$ more sheep stock units than the NZMWBES farms $(79 \%$ v. $67 \%)$. These differences were probably due to $48 \%$ of the farms in the NZMWBES sample being situated in the North, and South Auckland regions where farms are smaller (297 ha) and the proportion of sheep stock units carried is low (48\%).

\section{FFR sample - production and profitability}

A comparison of the physical and financial indices for the FFR sample and for each of the three profitability subgroups is presented in Tables 1 and 2 .

The potential carrying capacity and sheep to cattle ratios were, on average, similar for each of the subgroups. The high subgroup ran 9.57 stock units per ha, achieved $107 \%$ lambing and produced $6.4 \mathrm{~kg}$ of wool per sheep stock unit compared with 8.71 stock

Table 1 Comparison of the 1991 average physical performance levels of the FFR sample the high, medium and low farm surplus/ha subgroups and the NZMWBES class 4 survey farm average for 1991.

\begin{tabular}{|c|c|c|c|c|c|c|}
\hline & \multirow{2}{*}{$\begin{array}{l}\text { NZMWBES } \\
\text { Average }\end{array}$} & \multirow{2}{*}{$\begin{array}{c}\text { FFR Sample } \\
\text { Average }\end{array}$} & \multirow[b]{2}{*}{ SE } & \multicolumn{3}{|c|}{ Farm Profitability Groupings } \\
\hline & & & & High & Medium & LOW \\
\hline Size (ha) & 374 & 536 & 46 & $470^{\mathrm{a} 1}$ & $642^{a}$ & $499^{a}$ \\
\hline Stocking rate (su/ha $)^{2}$ & 9.9 & 9.32 & 0.17 & 9.58 & $9.68^{9}$ & $8.71^{b}$ \\
\hline Percent sheep $(\%)$ & 67 & 79 & 1.30 & $78^{a}$ & $78^{a}$ & 61 \\
\hline Lambing (\%) & 93 & 99 & 2.04 & $107^{a}$ & b & $90^{b}$ \\
\hline Wool production $(\mathrm{kg} / \mathrm{ssu})$ & $\begin{array}{r}5.4 \\
25.6\end{array}$ & $\begin{array}{r}5.5 \\
2005\end{array}$ & 0.16 & $\begin{array}{r}6.4^{\prime} \\
2716^{\prime \prime}\end{array}$ & $\begin{array}{r}4 \% \\
\end{array}$ & $\begin{array}{r}5.2^{\mathrm{b}} \\
2012^{\prime}\end{array}$ \\
\hline Labour (su/labour unit) & 2636 & 2895 & 142 & $2716 "$ & 2963' & 3012 \\
\hline $\begin{array}{l}\text { Potential stocking } \\
\text { rate (su/ha) }\end{array}$ & & 11.4 & 0.36 & II.P & $10.9^{9}$ & $11.7^{\mathrm{a}}$ \\
\hline
\end{tabular}

'Values followed by different letters are significantly different at $0<0.05$ level.

${ }^{2}$ Stock unit conversion ratios used are as reported by NZMWBES prior to 1991.

3 Potential stocking rate-assessed for each farm from land inventory maps (ref. NWASCO 1979). 
Table 2 Comparison of the 1991 average financial indices for the FFR sample the high, medium and low farm surplus/ha subgroups and the NZMWBES class 4 survey farm average.

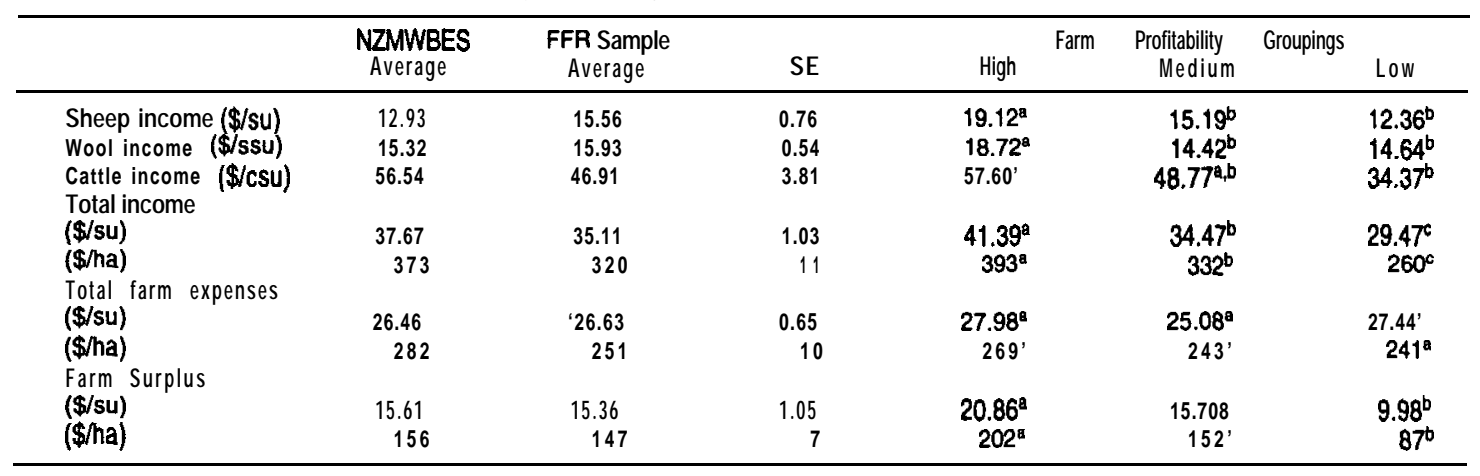

units per ha, $90 \%$ lambing and $5.2 \mathrm{~kg}$ of wool per sheep stock unit for the low subgroup.

Farmers in the high subgroup attained high levels of income from both sheep and beef enterprises, which was reflected in a higher total income per ha. Total income per ha for the high, medium and low subgroups was respectively $\$ 393, \$ 332$ and $\$ 260$. Levels of farm expenditure did not differ significantly among any of the three subgroups. Higher levels of per ha income did not, therefore, require higher levels of farm inputs.

\section{Willingness and ability to change}

Change in the context of this paper is defined as the adoption and/or implementation of a technology or management system that is expected to lead to an increase in profitability per stock unit or per ha. Farmers are willing to change if they believe the perceived benefits from change exceed the perceived costs and they have the necessary resources to change.

The willingness and ability of farmers, in each of the three profitability subgroups, is shown in Table 3. Seventy-five percent of farmers in the sample were willing to change. However, only $22 \%$ (13 of 60) were in a position to change and most of these farmers were in

Table 3 Comparison of FFR sample fanners' attitude and ability to change for the total sample and for each of the three high, medium and low profitability subgroups, and number of farmers in each category with insufficient levels of cash surplus.

\begin{tabular}{|c|c|c|c|c|c|c|}
\hline \multirow[b]{2}{*}{$\begin{array}{l}\text { Attitudelability } \\
\text { to chanqe }\end{array}$} & \multirow{2}{*}{$\begin{array}{c}\text { Farm } \\
\text { High } \\
N=20\end{array}$} & \multicolumn{3}{|c|}{ Profitability Groupings - } & \multirow[b]{2}{*}{$\begin{array}{l}\% \text { of } \\
\text { Total }\end{array}$} & \multirow[b]{2}{*}{$\begin{array}{c}\text { Insufficient } \\
\text { Cash Surplus }\end{array}$} \\
\hline & & $\underset{N=20}{\text { Medium }}$ & $\begin{array}{l}\text { Low } \\
N=20\end{array}$ & $\begin{array}{l}\text { Total } \\
\mathrm{N}=60\end{array}$ & & \\
\hline Unwilling & 2 & 8 & 5 & 15 & $25 \%$ & 3 \\
\hline Willing . & 18 & 12 & 15 & 45 & $75 \%$ & 26 \\
\hline - Willing and able & 5 & 4 & 4 & 13 & $22 \%$ & 4 \\
\hline - Willing but unable & 13 & 8 & 11 & 32 & $53 \%$ & 22 \\
\hline
\end{tabular}

the process of implementing change. The changes included: increasing the cattle to sheep ratio, the introduction of new pasture species and the adoption of objective stock selection methods.

Of the 15 (out of 60) farmers unwilling to change, 13 were older farmers nearing retirement, or farmers satisfied with the current level of output from their farming system. These farmers were more likely to adopt products and innovations that required little or no adjustment to their existing system. The remaining two farmers were committed to low input systems and were unwilling to outlay cash on anything but essential farm operating expenses. Their cash requirements were being met, even at low levels of stock performance, because cash saved over the years had been invested in more land.

Farmers at low levels of profitability may be expected to be more willing to change. The data indicate, however, that similar proportions of farmers from each of the three subgroups were willing to change.

\section{Insufficiency of cash income}

Farmers were asked to assess their farm businesses cash surplus in 1991 as sufficient or insufficient to meet the consumption needs of their family at that time. The number of farmers with insufficient cash surplus is presented in Table 3 in relation to the farmers willingness and ability to change. The constraints to change are outlined in Table 4.

Of the farmers who were willing to change $58 \%$ ( 26 of 45 ) assessed their cash surplus to be insufficient and $85 \%$ of these farmers (22 of 26) were in fact unable to change.

Three farmers unwilling to change also assessed their cash surplus as 
insufficient. These farmers were nearing retirement, receiving income from offfarm or relying on off-farm factors to increase their future level of income.

\section{$M$ ajor constraints to change}

Of the 45 farmers willing to change, 32 faced a major constraint (Table 4) which limited their ability to change. Sixteen farmers had scarce financial resources and were prepared to spend money only on essential inputs.. This financial situation was, for 10 farmers, due to a high level of debt servicing and, for the remaining 6 farmers, due to an under-developed low income-generating farm. Of these 16 farmers 15 assessed their farm business cash surplus as insufficient to meet the cash needs of their family.

Six farmers were achieving high levels of performance relative to the production potential of their land and felt they had limited opportunity to increase their production or profitability. Four of these farmers assessed their cash surplus as insufficient.

Four farmers did not have full management decision control over the property and their decisions were dictated by individuals who were unwilling to change. Two of these farms were assessed as generating an insufficient cash surplus.

The major constraint facing the remaining 6 farmers was labour; its availability, its cost and an unwillingness by the farmer to employ and supervise additional labour. Five of the farmers facing this constraint were generating sufficient levels of cash surplus from the farm. Labour was identified, more frequently, as a constraint in the high subgroup and the under-developed state of the farm was a constraint more commonly identified by farmers in the low subgroup.

\section{Discussion}

Many farmers, concerned with the wellbeing and security of their families, continue to face a very real need to increase productivity and profitability. The data presented in this paper indicate that factors other than farmers' willingness to change will constrain the extent to which farmers can adopt technology and implement change.

There is still work to be done to define the types of technology that are appropriate to farmers' circumstances. The implications of the FFR findings to date are that many farmers are likely to find technologies useful where there is no requirement for the reinvestment of income or extra labour. Technologies are likely to be viewed as appropriate if the benefits of implementing the change can be clearly recognised as contributing to the improvement of the farming system as a whole. Increased returns from adopting technology will be assessed by the effect the technology has on the total cash surplus from the farm rather than on the per hectare or per head returns.

Circumstances that contribute to a level of cash surplus that is insufficient to meet the needs of the farming family appear to be an important factor in determining whether or not farmers are willing to make changes to their current farming system and management. However the absolute level of cash surplus that constitutes sufficient or insufficient varies between farmers and their circumstances. There is, moreover, little researched information available as to farmers' perceptions of the risk they associate with change. It seems likely that these perceptions will also vary between farmers and their circumstances. These matters need to be addressed if phase two of the FFR programme is to generate strategies and technologies that farmers are likely to implement.

\section{ACKNOWLEDGEMENTS}

The FFR programme is funded by Massey University, AGMARDT and the C. Alma Baker Trust.

Recognition is also made of the contribution of FFR sample farmers who continue to collaborate willingly and freely to this research programme.

\section{REFERENCES}

Fairweather, J.R.; Keating, N.C. 1990. Management styles of Canterbury Farmers. A study of goals and success from the farmers' point of view. Research report No. 205, Agribusiness and Economics Research Unit, Lincoln University.

McRae, A.F.; Anderson, F.M.; Brazendale, R. 1993. Applying Farmer First Research in New Zealand. Proceedings of the XVII International Grassland Congress: $\quad 637-639$.

Norusis, M.J. 1988. SPSS/PC+V2.0 Basic Manual. SPSS Inc., Chicago. 
NZMWBES. 1992a. The New Zealand sheep and beef farm survey 1990-91. Publication No. 2052, New Zealand Meat and Wool Boards' Economic Service. NZMWBES, 1992b. Annual review of the New Zealand sheep and beef industry 1991-92. Publication No. 2049, New Zealand Meat and Wool Boards' Economic Service.

Reynolds, R.; Moore, W. 1990. Farm prices and costs. pp.137-156 In Farming without subsidies, New Zealand's recent experience. Sandrey, R.; Reynolds, R. eds.

Science and Technology Expert Panel 1992. Long term priorities for the public good science fund. Ministry of Science, Research and Technology, Wellington. 